\title{
ASPECTOS PRAGMÁTICOS DA NEGAÇÃO SENTENCIAL
}

\author{
Marcos Goldnadel* \\ Luana Santos de Lima*
}

\begin{abstract}
RESUMO: Há um consenso na literatura linguística de que enunciados negativos são marcados em relação às suas contrapartes afirmativas, por veicular conteúdo de algum modo ativo na troca discursiva. Esse estatuto especial é evidente em enunciados claramente marcados, como os que envolvem negação metalinguística, mas parece estender-se mesmo a enunciados neutros. Além disso, em algumas línguas, como o português, soma-se o fato de que a negação sentencial apresenta realizações alternantes, dispondo de formas canônicas de negação (Não vou) e de formas não canônicas (Não vou não; Vou não), estratégias diferentes para as quais supõem-se funções pragmáticas distintas. Este artigo procura apreciar criticamente algumas hipóteses sobre a pragmática de enunciados negativos e, com base em dados do projeto VARSUL, avaliar sua validade. Dessa forma, pretende-se contribuir para a compreensão pragmática da negação em PFB.
\end{abstract}

PALAVRAS-CHAVE: Negação sentencial - Pragmática - Português brasileiro

ABSTRACT: There is a consensus in the linguistic field regarding the fact that negative utterances are marked when compared to their affirmative counterparts, in that they convey content which is in some way activated during the conversational exchange. This special status is manifest in marked utterances, such as those displaying metalinguistic negation, and is also present in neutral utterances. Besides that, in some languages, such as Portuguese, it is important to consider that sentential negation displays alternative realizations, having canonical forms (Não vou) and non canonical forms (Não vou não; Vou não), strategies which have been hypothesized as having different pragmatic functions. This article proposes a critical assessment on some hypothesis concerning the pragmatics of negative utterances and, based on data from VARSUL project, an evaluation of their accuracy. Thus, the aim of this article is to contribute to the understanding of the pragmatics of negation in $B P$.

KEY-WORDS: Sentence negation - Pragmatics - Brazilian Portuguese

\section{INTRODUÇÃO}

Um dos temas relevantes dos estudos no campo da produção de sentido nas línguas naturais é a opção pela análise de fenômenos nos campos vizinhos da Semântica e da Pragmática. A divisão de tarefas entre as duas disciplinas tem sido objeto de um debate permanente, em movimentos que se alternam frequentemente em direções opostas. Apenas para citar um exemplo, o estudo da articulação informacional de enunciados, que se desenvolveu de modo consistente ao abrigo de teorias de funcionalistas (cf. Ilari 1992) - sendo essa articulação tratada, portanto, como um fenômeno pertencente ao que se poderia chamar de uma pragmática da frase (cf. Lamprecht, 1994) -, em determinado momento, passou a constituir-se também como

\footnotetext{
UFRGS, Professor na Universidade Federal do Rio Grande do Sul, Doutor pela Pontifícia Universidade Católica do Rio Grande do Sul, emegold@gmail.com

* UFRGS, mestranda em Letras - Linguítica na Universidade Federal do Rio Grande do Sul, lu.santosdelima@gmail.com
} 
preocupação de teorias semânticas, que passaram a considerar a noção de foco passível de descrição formal no âmbito desta disciplina.

A divisão de trabalho entre as disciplinas, mais do que um debate engajado, tem sido consequência do empenho de apresentar descrições e explicações adequadas no âmbito dos paradigmas teóricos que se constituem ao longo da história das disciplinas Semântica e Pragmática. Subjaz a essas discussões um esforço de separar o que deve ser tratado como decorrência de convenções e o que deve ser visto como reflexo da dinâmica conversacional. No campo da Pragmática, testemunham-se alguns esforços de realocar o que, não sem alguma contrariedade, em algum momento foi considerado como pragmático e convencional no que poderia ser visto como pragmático e conversacional. Um exemplo de empreendimento nesse sentido é o trabalho de Diane Blackemore $^{1}$, que, no paradigma da Teoria da Relevância, procura reenquadrar as tradicionais implicaturas convencionais do paradigma griceano em uma perspectiva conversacional de base cognitiva.

Ainda nessa esfera, é conhecido o debate em torno do enquadramento apropriado para as implicaturas conversacionais generalizadas, que, pelo seu caráter estável, poderiam ser consideradas matéria da Semântica, e não da Pragmática. Muitos argumentos foram esgrimidos, por exemplo, no sentido de demonstrar que a leitura exclusiva da conjunção ou é um caso de implicatura generalizada, apesar de uma aparente convenção nas línguas naturais. O fato é que, como bem observa Levinson (2000), há uma espécie de intrusão da Pragmática na Semântica, o que dificulta uma delimitação mais precisa dos fenômenos no campo da significação.

Nem sempre, no entanto, é possível defender com empenho semelhante um nível em detrimento de outro na descrição de um determinado fenômeno. Em sua Natural History of Negation, Laurence Horn (Horn, 2001) evidencia os problemas que a interação entre determinados operadores e negação colocam para uma teoria semântica de base formal. Interpretações muito estáveis associadas e enunciados com operadores modais, se descritas a partir de um enquadramento semântico, provocariam um colapso de consequências desastrosas. Um dos casos em pauta seriam enunciados como (1), que permitem a inferência em (2).

(1) Talvez ele venha.

(2) Talvez ele não venha.

A questão a ser respondida é a seguinte: o conteúdo apresentado em (2) é uma inferência semântica ou pragmática da enunciação do conteúdo em (1). Dada a regularidade da inferência, a sua independência de contexto, a tentação seria enquadrar o conteúdo no âmbito das inferências semânticas. Essa inferência seria um novo axioma a ser considerado na semântica das línguas naturais, apresentado em (3).

(3) $\diamond p \rightarrow \diamond-p$

Esse axioma deveria, num perspectiva semântica, somar-se a outros já reconhecidos, em (4) e (5).

${ }^{1}$ Cf. Blackemore (2002)

Cadernos do IL. Porto Alegre, n. ${ }^{\circ}$ 42, junho de 2011. p. 236-259. 
(4) $\mathrm{p} \rightarrow \diamond \mathrm{p}$

(5) $\mathrm{p} \rightarrow-\diamond-\mathrm{p}$

O axioma (4) diz que se uma proposição é necessária, então ela é possível. O axioma (5) diz que se uma proposição é necessária, então não é possível que ela não seja verdadeira. O problema é que esses três axiomas, tornam o sistema inconsistente, como demonstra a prova a seguir.
(1) $\mathrm{p}$
S.
(2) $\diamond \mathrm{p}$
de (1) pelo axioma 4
(3) $\diamond-p$
de 2 pelo axioma 3
(4) $-\diamond-p$
de 1 pelo axioma 5
(5) $(\diamond-p) \&(-\diamond-p)$
de (3) e (4) por Introdução do \&
(6) $-\mathrm{p}$
de (2) a (7) por Redução ao Absurdo.

O que a prova acima demonstra é que, considerando-se os três axiomas propostos, jamais seria possível supor uma verdade necessária, porque ela sempre conduziria a uma contradição ${ }^{2}$. Mais que isso, uma verdade necessária implicaria sua própria falsidade. A consequência seria, então, considerar a sentença (6) automaticamente contraditória.

(6) É necessário que Deus exista.

Ora, independentemente das crenças que uma pessoa possa ter, ela deve admitir que uma sentença como (6) não é, nem soa como contraditória.

Felizmente, a inferência (2) a partir de enunciados como (1) pode ser facilmente explicada no campo da Pragmática. Como bem demonstra Gazdar (1979), os itens lexicais necessário e possível formam uma escala de informatividade, o que permite considerar o conteúdo em (2) uma implicatura de quantidade do enunciado (1). Essa predição se confirma pela possibilidade de cancelamento explícito do conteúdo em (2) o que não seria possível se a inferência fosse semântica -, como ilustra. (7).

(7) Talvez ele venha; na verdade, ele vem de qualquer jeito.

O reconhecimento de escalas de informatividade, necessárias para descrever a inferência em (2) - que a Pragmática deve a Horn - permitiu descrever outros fenômenos que, de outra forma, seriam um mistério para teorias semânticas. Digno de nota é o reconhecimento de um tipo de negação que não poderia ser vista como estando a operar sobre conteúdo semântico: a negação metalinguística. Um caso de negação metalinguística pode ser visto em (8).

${ }^{2}$ Esse mesmo problema é abordado em Gazdar (1979). 
(8) A: Como estava o jantar que preparei?

B: O jantar não estava bom. Estava ótimo.

Entendida como um operador semântico, a negação do primeiro enunciado do falante B em (8) deveria, em combinação com o segundo enunciado, produzir um discurso contraditório. Sabe-se, no entanto, que interlocutores exploram frequentemente uma ambiguidade associada ao uso do operador de negação, que pode ser interpretado como um estando a operar sobre conteúdo semântico ou sobre conteúdo pragmático. Neste caso, o que B nega com seu primeiro enunciado não é conteúdo semântico de bom (o que permitiria a inferência pelo seu antônimo: ruim), mas o conteúdo pragmático que estaria associado ao enunciado afirmativo $O$ jantar estava bom.

Casos como (8) são apenas um dos aspectos entre tantos a serem considerados quando se trata de enunciados negativos nas línguas naturais. Aqui, mais do que estabelecer uma divisão de trabalho entre a Semântica e a Pragmática, trata-se de ver que aspectos da negação podem ser vistos no âmbito de cada disciplina, uma vez que parece evidente que a negação requer contribuições desses dois campos de análise.

Não é apenas no campo dos proferimentos marcados, como (8), que a análise pragmática precisa ser invocada quando se trata de analisar a negação nas línguas naturais. Os enunciados negativos têm sido considerados como enunciados com características pragmáticas especiais quando comparados a suas contrapartes afirmativas. Para complicar um pouco ainda a situação, muitas línguas experimentam fases em que a negação sofre uma duplicação - apresentando enunciados com dupla negação, como o francês e até mesmo o português -, o que parece estar fortemente associado a estratégias de caráter conversacional. Tudo isso sugere a relevância de compreender, a par dos aspectos semânticos da negação, a pragmática dos enunciados negativos, tema deste artigo.

No caso do português falado no Brasil (PFB), a existência de três estratégias de negação sentencial chama atenção, de acordo com as observações realizadas por um número expressivo de estudos, como se pode observar nos exemplos a seguir.

(9) José não foi à festa. (NEG1)

(10) José não foi à festa não. (NEG2)

(11) José foi à festa não. (NEG3)

A sentença (9) ilustra a negação canônica, que é pré-verbal (Não VP). Em (10), observa-se a dupla negação (Não VP não) e, em (11), a negação pós-verbal (VP não), de agora em diante, respectivamente, NEG1, NEG2 e NEG3.

A existência de três tipos de negação sentencial no português falado no Brasil é digna de nota, segundo observação de Schwenter (2005), visto que a grande maioria das línguas apresenta, no máximo, em um mesmo período, duas estratégias. Essa variação de uso, no entanto, não é uma novidade na história das línguas. $O$ francês e o inglês, por exemplo, experimentaram estágios nos quais duas estratégias de negação coexistiram, 
passando pelo chamado Ciclo de Jespersen ${ }^{3}$. O português brasileiro é a única língua românica, no entanto, a aceitar o uso concomitante dessas três estratégias.

No caso do PFB, sabe-se que a distinção entre os usos apresentados em (9), (10) e (11) não é de ordem semântica, uma vez que todas têm o mesmo sentido proposicional. Cabe, então, investigar se há alguma explicação capaz de esclarecer as razões dessa variação. Uma provável explicação de ordem pragmática para a existência de três estratégias de negação sentencial no PFB já é esboçada por Shwenter (2005, 2006). Também Schwegler (1991) apresenta hipóteses a respeito da pragmática da negação.

No Brasil diversos estudos (Camargos (2001), Furtado da Cunha (2001), Roncarati (2006), Souza (2004)) têm se voltado para o fenômeno da variação do uso da negação sentencial. Não se vê nesses estudos, no entanto, qualquer análise que inclua considerações de ordem pragmática. Este trabalho pretende contribuir para a compreensão do fenômeno da negativa sentencial ${ }^{4}$, a partir da contribuição dos autores mencionados e da observação de dados.

$\mathrm{O}$ trabalho está organizado da seguinte forma. $\mathrm{Na}$ seção 2, são realizadas algumas considerações sobre a semântica de enunciados com o operador de negação. A seção 3 trata de abordagens dedicadas à descrição do comportamento pragmático da negação canônica, que se expressa pelo operador colocado apenas antes do sintagma verbal. A seção 4 apresenta algumas abordagens que se dedicaram a analisar enunciados com negação sentencial não canônica. Na seção 5, realiza-se uma análise crítica das diversas abordagens consideradas. A seção 6 apresenta as considerações finais.

\section{CONSIDERAÇÕES SOBRE A SEMÂNTICA DA NEGAÇÃO}

A negação tem lugar de destaque nos estudos da área de Semântica. Há uma série de questões envolvendo a negação que merecem atenção em abordagens que se voltam para semântica das línguas naturais, uma vez que, de modo geral, as línguas apresentam diversas formas de expressar semanticamente a negação de conteúdos veiculados nos enunciados de sentenças. Pode-se falar da existência de negação lexical, negação de constituinte e negação sentencial.

A negação lexical é aquela que opera sobre o sentido de vocábulos, manifestando-se, principalmente, através de recursos de natureza morfológica. Normalmente, a negação lexical é produzida pela utilização de prefixos, como in-/im-, des-, a, como se pode observar a seguir.

(12) a. Maria está impaciente com a demora na divulgação do resultado do ENEM.

b. Os alunos exigiram que os membros do DCE agissem de forma apartidária.

\footnotetext{
${ }^{3}$ Ciclo de Jespersen é um termo utilizado para referir-se a um processo de mudança da posição do advérbio de negação, que oscila entre a posição pré-verbal e a posição pós-verbal.

${ }^{4}$ As negações sentenciais que tem como operadores quantificadores negativos (nenhum, ninguém, nada, nunca) não serão alvo de investigação nesse estudo, apenas aquelas nas quais o advérbio de negação não atua como operador.
} 
Além dos prefixos, o advérbio de negação não pode restringir seu escopo sobre o conteúdo expresso por um item lexical, operando de forma similar a um prefixo, como ilustra (13).

(13) a. Esta reunião é proibida para não iniciados.

b. A festa foi planejada pelo pessoal não docente.

Em (13) o advérbio não opera exclusivamente sobre os predicados iniciados e docente, denotando o complemento do conjunto dos iniciados e dos docentes no domínio de indivíduos próprios para a predicação.

A negação de constituinte, como diz Guedes (2001), afeta o constituinte sintagmático que precede e é utilizada, na maioria das vezes, para fazer uma correção, em que se pretende preservar apenas parte de um conteúdo previamente enunciado ou inferido. Nesses casos, a negação opera apenas sobre um determinado constituinte, anunciando a necessidade de sua substituição por outro mais apropriado, como se pode observar nas frases a seguir.

(14) a. Esta reunião foi feita não para iniciados, mas para leigos.

b. A festa foi planejada não pelo pessoal docente, mas pelo discente.

Já na negação sentencial, o escopo do operador negativo recai sobre a proposição expressa pela oração. Considere as seguintes sentenças.

(15) José não gosta de alho.

(16) Ninguém terminou o trabalho de português.

Observe que, nas sentenças (15) e (16), o operador negativo não e o quantificador negativo ninguém tomam como escopo um conteúdo proposicional. Nestes casos, negam os conteúdos proposicionais expressos pelas sentenças em (17) e (18).

(17) José gosta de alho.

(18) Alguém terminou o trabalho de português.

O quadro exposto aqui é um quadro geral e bastante simplificado dos recursos disponíveis para expressar a ideia de negação e do que significa a negação de uma sentença ou constituinte sintagmático. No campo da investigação semântica, seria possível, ainda, problematizar a negação em diversas direções, como, por exemplo, investigar as fronteiras entre negação lexical e negação sentencial nas situações em que a distinção merece maior atenção, como é o caso da palavra impossível, em que um recurso morfológico é utilizado na negação de um operador, tendo, portanto, valor sentencial.

Os problemas relacionados à negação, no entanto, não se restringem aos seus aspectos semânticos. Muito se discutiu na literatura a respeito de pressuposição, por exemplo, sobre o papel de certos padrões prosódicos marcados presentes em sentenças 
negativas. A negação metalinguística, como ficou conhecida a partir do trabalho de Lawrence Horn (cf. Horn(1985), Carston (1996)), ocupou um considerável espaço na discussão sobre os aspectos pragmáticos da negação. Autores como Givón $(1978,1984)$ têm chamado a atenção para o fato de que o uso da negação envolve mais do que aspectos de natureza semântica, nos casos da negação sentencial. Nas próximas seções, são discutidos aspectos pragmáticos envolvidos em enunciados negativos.

\section{A PRAGMÁTICA dA NEGAÇÃO CANÔNICA (PRÉ-VERBAL)}

Os autores que tratam da pragmática da negação como (Givón $(1978,1984)$, Hans Kamp (1993), Horn (1985), Carston (1996)), em sua maioria, descrevem apenas a estratégia de negação pré-verbal (canônica). Esse fato pode ser explicado pelo fato de seus estudos tomarem por base línguas que não apresentam, pelo menos de modo significativo, estruturas com negação pós-verbal.

Esta seção apresenta algumas considerações que procuram descrever a pragmática da negação canônica. Há um certo consenso, na literatura linguística, sobre o caráter pressuposicional de enunciados negativos. Esse consenso chega, em alguns casos, a estimular a postulação de um ato de fala distinto, o de denegar, como se observa no trecho a seguir.

\footnotetext{
Entre os vários outros atos de fala há um que nem sempre é distinguido da asserção e que, evidentemente, tem uma associação muito próxima com ele. É a denegação. A situação paradigmática em que a denegação ocorre é aquela em que o receptor entende o que é dito a ele, rejeita e deixa isso ser percebido pelo falante..

Em todos esses casos, o efeito da denegação é repudiar algo que foi posto tentativamente ou confidentemente por alguma outra pessoa; é rejeitar, como a presente teoria sugere, o 'quadro' que o outro falante apresentou como certo ou possivelmente correto.

(Kamp e Reyle, 1993, p. 100, apud Goldnadel, 2004)
}

Um autor representativo desta hipótese é Givón, que se posicionou de forma bastante consistente a favor da consideração da negação como um ato de denegar. $\mathrm{O}$ autor começa por registrar a limitação de uma abordagem que associe ao operador de negação apenas o seu valor lógico. Essa limitação fica evidente quando se comparam frases que, em princípio, deveriam ser sinônimas, como (19) e (20).

(19) Carlos não é feliz.

(20) Carlos é infeliz.

As duas sentenças deveriam apresentar Carlos em um estado de não felicidade, mas não de tristeza, pois visto do ponto de vista lógico, uma mesma função semântica para o advérbio de negação e para o prefixo negativo poderia ser suposta. No entanto, não é o que normalmente se depreende dos usos desses tipos de sentença. Normalmente, o entendimento seria o de que Carlos é uma pessoa triste. Isto é, nos dois casos, em vez da leitura contraditória esperada, ocorre uma leitura em que não ser feliz e ser infeliz 
integram leituras contrárias (embora o enunciado com a negação prefixal represente mais marcadamente a leitura contrária).

Para Givón, uma outra diferença entre (19) e (20) pode ser apontada, a saber, a de que a sentença que apresenta o advérbio de negação faz supor um interlocutor sendo contrariado em suas convicções. Para o estudioso, portanto, uma sentença como (19) tem uma expectativa de fundo, que seria a proposição afirmativa correspondente em relação à negativa enunciada. Givón ilustra esse ponto com os seguintes exemplos ${ }^{5}$.

(21) A: Quais são as novas?

B: O presidente morreu.

A: Oh, quando? Como?

(22) A: Quais são as novas?

$\mathrm{B}$ : O presidente não morreu.

A: Por quê? Ele estava mal?

A sentença negativa, em (22), causa estranheza ao ouvinte, o que pode ser percebido em sua resposta, indicando que alguma coisa está errada na proposição considerada como parte do fundo conversacional. O interlocutor B em (22), parece ter assumido, assim, que A soubesse ou tivesse ouvido falar sobre o mal estado de saúde do presidente. Não sendo este o caso, não haveria motivo para dizer que o presidente não morreu. Já em (21), o interlocutor B, ao responder que o presidente morreu, está apenas informando, esta resposta não pressupõe alguma informação sobre a saúde do presidente.

Estes exemplos retirados de Givón (1978 e 1984) ilustram uma concepção do autor acerca da asserção negativa, a de que esta é um ato de fala outro, o ato de denegar, que, diferentemente do assertivo, é usado para contradizer, corrigir (e não apenas informar). A negação seria pressuposicional. E o que se nega é a correspondente afirmativa, a informação de fundo, que está, de certa forma, pressuposta. ${ }^{6}$

Para Givón, a informação de fundo pode ser velha no discurso em função de ter sido trazida pelo próprio interlocutor em sua fala para depois ser negada (23), ou pode ter sido apresentada na fala do outro (24). E também pode ser uma informação genérica culturalmente compartilhada (25).

(23) João disse que fez o trabalho sozinho, mas eu acho que não.

(24) A: Então quer dizer que compraste um carro novo.

B: Não, não comprei. Por que dizes isso?

\footnotetext{
${ }^{5}$ Os exemplos (3) e (4) são traduções nossas dos exemplos originais de Givón (1978 e 1984).

${ }^{6}$ É importante esclarecer que o sentido de pressuposicional associado ao uso de enunciados negativos é distinto daquele associado ao uso de gatilhos. $\mathrm{O}$ fato de um enunciado negativo ser pressuposicional, nesse contexto, não significa que expresse um conteúdo compartilhado entre os interlocutores, mas que o falante age do modo a fazer supor que seu interlocutor sustente um ponto de vista contraditório com o seu. $\mathrm{O}$ fato de ser uma atitude em que o falante parece assumir que seu interlocutor esteja previamente em um estado de crença específico estimulou o uso da expressão pressuposição. É nesse sentido, que se distancia daquele que se desenvolveu a partir da discussão dos gatilhos, que o termo é usado ao longo deste trabalho.
} 
(25) Certa vez apareceu um homem que não tinha cabeça...

Em (23), a proposição que serve de fundo é velha no discurso de forma explicita, trazida pelo próprio falante, que primeiro a lança para depois poder negá-la. $\mathrm{Na}$ sentença seguinte, (24), o falante nega uma proposição que foi posta pelo outro interlocutor, é velha no discurso também de forma explícita. E em (25), o que acontece é uma quebra na informação compartilhada culturalmente de que todo homem tem uma cabeça.

O caráter marcado da sentença negativa em relação à afirmativa, argumenta Givón, pode ser explicado a partir da ontologia de estados e eventos negativos. $\mathrm{O}$ autor quer apontar para o fato de que uma circunstância é composta acontecimentos e não acontecimentos. Para ele, acontecimentos ou eventos são probabilisticamente menos esperados e menos frequentes do que não acontecimentos ou não eventos. Essa seria razão para que eventos sejam mais salientes do que os não eventos, configurando o que chama de foreground. Já os não eventos integram o chamado background.

Tomando por base as considerações de Givón, pode-se esperar que as pessoas estejam mais atentas, no seu entorno, aos eventos do que aos não eventos, uma vez que são aqueles que carregam maior conteúdo informativo. Da mesma forma, esperara-se que interlocutores, em suas trocas conversacionais, reportem eventos, tipicamente veiculados por enunciados afirmativos. De fato, parece que essa é a norma. Qualquer levantamento estatístico mostrará que grande parte das sentenças enunciadas são afirmativas. Sendo assim, poderíamos questionar-nos sobre qual seria, então, a função de enunciados negativos, uma vez que veiculam não eventos, que, segundo Givón, seriam menos informativos. Para o autor, a enunciação de uma sentença negativa seria como um jogo de linguagem, no qual um não evento, tipicamente parte do background, é apresentado como foreground, jogando para o background a proposição que veicularia o evento. Daí o sentimento de que a proposição contraditória com a expressa pela sentença negativa enunciada seria um conteúdo sustentado pelos interlocutores, uma espécie de pano de fundo.

Ainda há a questão dos possíveis motivos que levam um falante a utilizar uma asserção afirmativa ou negativa. No ato de denegar, o falante não está interessado em comunicar uma nova informação, mas antes corrigir um possível mal entendido nas crenças do ouvinte. E isso se reflete em como se assume o background em ambos os atos. Se no ato de assertar o falante acredita que o ouvinte não sabe o que ele sabe, no de denegar o falante acredita que sabe melhor e que o ouvinte sabe errado.

Todos os exemplos apresentados sugerem fortemente um caráter marcado para enunciados negativos. Assim, as observações de Givón parecem ir ao encontro das intuições dos falantes de um modo geral. No entanto, deve-se atentar que o conjunto de casos observados por Givón limita-se a enunciados negativos que se caracterizam por apresentar a negação em orações absolutas ou orações principais, e não serem amostras da fala natural. É bem possível que a observação do operador de negação em trechos de fala espontânea ou em outros contextos sintáticos permita aprimorar a visão sobre os aspectos pragmáticos da negação e sobre os modos de organizar a informação no interior do período. Por isso, a pretensão de considerar enunciados negativos como a 
expressão de um ato de fala específico, o de denegar, deve, considerar a necessidade de ampliar o espectro de enunciados a serem observados.

\section{AS NEGAÇÕES NÃO CANÔNICAS}

Em razão da existência de uma alternância entre três estratégias de negação, a negação canônica, a dupla negação e a negação pós-verbal, muitos autores têm se voltado para o estudo dos fenômeno da negação sentencial em português brasileiro. $\mathrm{Na}$ negação canônica, abordada na seção anterior, o advérbio de negação não está posicionado antes do sintagma verbal. $\mathrm{Na}$ dupla negação, há duas ocorrências do operador $n \tilde{a} o$, antes e depois do sintagma verbal. Já a negação pós-verbal, pela presença do não após o sintagma verbal.

(26) Augusto não sabe andar de bicicleta. (NEG1)

(27) Augusto não sabe andar de bicicleta não. (NEG2)

(28) Augusto sabe andar de bicicleta não. (NEG3)

É consenso entre os diversos autores que, em todos esses casos, não há diferenciação no significado do conteúdo proposicional. As sentenças (26), (27) e (28) negam o fato de Augusto saber andar de bicicleta, isto é, tem o mesmo significado.

No Brasil, a existência das diversas estratégias tem estimulado uma série de estudos, predominantemente no campo da análise sociolinguística. Uma preocupação encontrada em parte desses estudos é determinar se o português brasileiro experimenta uma variação estável, determinada principalmente por variáveis sociais, ou se está passando por um processo de mudança linguística. Fundamentalmente o que se pretende descobrir é se a negação sentencial no português brasileiro está passando pelo Ciclo de Jespersen.

Alguns dos estados brasileiros investigados em estudos realizados sobre as estratégias de negação são Ceará, Bahia e Rio Grande do Norte, da região nordeste, e Minas Gerais e Rio de Janeiros, da região sudeste. O estudo que tomou como corpus o falar do estado do Ceará foi o de Roncarati (2006). A autora descreveu os usos da negação sentencial do falar de Fortaleza através de uma análise quantitativa de um corpus de entrevistas sociolinguísticas. Por meio do programa Varbrul, obteve dados estatísticos sobre a frequência de usos das três estratégias de negação, em diferentes contextos linguísticos.

A autora considerou em sua análise diferentes fatores: tipo de frase, posição da oração negada dentro do turno, tipo de sujeito, tipo de constituinte pós verbal, escopo da negação, e replicação de verbo presente em turno imediatamente anterior. A autora afirma ter extraído os dados de 822 sentenças negativas proferidas por 12 informantes cearenses de 10 a 42 anos. Após submissão ao programa Varbrul, avaliou idade e sexo como variáveis sem peso significativo no uso de NEG3 vs NEG1 e NEG2. 
A tabela a seguir resulta da simplificação da tabela 1 apresentada no artigo original da autora, originalmente apresentada em Calvacante (2007) ${ }^{7}$.

Tabela 1: Distribuição das estratégias de negação sentencial em Fortaleza, corpus Roncarati (1996)

\begin{tabular}{|l|l|l|l|l|}
\hline & Neg 1 & NEG2 & NEG3 & Total \\
\hline $\begin{array}{l}\text { Número de } \\
\text { ocorrências }\end{array}$ & 625 & 149 & 39 & 813 \\
\hline Porcentagem & $77 \%$ & $18 \%$ & $5 \%$ & $100 \%$ \\
\hline
\end{tabular}

Fonte: Cavalcante (2007)

Embora haja uma grande diferença percentual entre o uso de NEG1 em relação a NEG2 e NEG3, a quantidade de ocorrências de negação não canônica encontrada pela autora já pode ser considerada significativa.

Assumindo uma posição funcionalista, a autora adere à tese givoniana de que toda negação é pressuposicional. Mesmo que sua caracterização pragmática das negativas sentenciais não seja conclusiva, a autora sugere como possibilidade uma análise em que a negação canônica teria um caráter pressuposicional neutro, factual. A dupla negação teria a função discursiva de preservação da face. Por sua vez, NEG3 seria característica de situações em que o falante não alimenta expectativa de interação continuada, sendo uma forma "despachada" de negar.

A variação das negativas sentenciais no dialeto mineiro foi analisada por Camargos (2000) através de um corpus da cidade de Belo Horizonte. Diferentemente, da análise de outros estudiosos, o autor considera a dupla negação realizada com outro item negativo em posição pré-verbal, além do operador não. Assim, para este autor, o enunciado em (29), é classificado como NEG2.

(29) ...nunca cheguei a gostar muito não. (cf. Camargos, 2000:3)

Nessa perspectiva, a distribuição das três estruturas negativas encontradas em seu corpus pode ser representada pela tabela 2 (adaptada do autor).

Tabela 2: Distribuição das estratégias de negação sentencial em Belo Horizonte, corpus Camargos (2000)

\begin{tabular}{|l|l|l|l|l|}
\hline & Neg 1 & NEG2 & NEG3 & Total \\
\hline $\begin{array}{l}\text { Número de } \\
\text { ocorrências }\end{array}$ & 687 & 265 & 28 & 980 \\
\hline Porcentagem & $70 \%$ & $27 \%$ & $3 \%$ & $100 \%$ \\
\hline
\end{tabular}

Fonte: Camargos (2000:4)

Observa-se que a ocorrência de dupla negação é maior nos dados de Camargos (2000), mas é difícil de dizer se isto é em função dos falantes mineiros utilizarem mais duplas

\footnotetext{
${ }^{7}$ A tabela apresentada, extraída de Cavalcante (2007:24) corrige a soma dos valores encontrada em Roncarati (1996:103).
} 
negações, ou pelo fato dele considerar também como NEG2 as que apresentam outro item negativo.

Em sua análise estatística dos dados, foi indicado como relevante, entre as variáveis sociais, apenas a faixa etária. Para o autor, isto sugere que o uso de variedades não canônicas cresce à medida que diminui a faixa etária, indicando uma possível mudança em progresso. Além dessa variável, o autor identificou uma série de outros fatores linguísticos favorecedores dos usos não canônicos de negação: tipo de constituição do núcleo verbal (um ou mais verbos), presença ou ausência de outro item negativo, posição do item negativo em relação ao verbo, realização ou não do sujeito pré-verbal, e realização plena ou não da negação pré-verbal.

O autor afasta-se da prática comum ao sugerir uma reelaboração da variável dependente em duas variantes: negativa pré-verbal (Neg V) e negativa pós-verbal (Neg $\mathrm{V} \mathrm{Neg}$ ) e (V Neg). Seu argumento é que a negação dupla se comportaria como a negação pósverbal. Para ele, o fato de haver uma alta frequência da partícula pré-verbal negativa na forma reduzida em sentenças cuja estratégia utilizada é a dupla negação, indicaria que o marcador reduzido está incorporado ao verbo.

Souza (2004) analisa os dados do corpus falado de uma comunidade rural quilombola de Helvécia ${ }^{8}$. Os dados brutos para as ocorrências de sentenças negativas são apresentados na tabela a seguir.

Tabela 3: Distribuição das estratégias de negação sentencial em Helvécia, corpus Souza (2004)

\begin{tabular}{|l|l|l|l|}
\hline & NEG1 & NEG2 e NEG3 & Total \\
\hline $\begin{array}{l}\text { Número de } \\
\text { ocorrências }\end{array}$ & 943 & 465 & 1408 \\
\hline Porcentagem & $67 \%$ & $33 \%$ & $100 \%$ \\
\hline
\end{tabular}

Fonte: Calvacante (2007)

Também, como se pode observar, há uma incidência bastante significativa de formas não canônicas de negação. O autor utiliza muitas das variáveis linguísticas encontradas em Roncarati (1996), acrescentando outras, tendo como resultado o seguinte envelope de variação: o tipo de oração, o tipo de sujeito, de complemento, e a característica léxico-semântica dos verbos, fatores sociais, tipo de frase e tipo de constituição do núcleo verbal.

Algo interessante a ser frisado no estudo de Souza é o fato de que são os idosos os que mais utilizam as formas de negação não canônica. Esse dado contrasta com os achados dos demais estudos. A alta incidência de dupla negação entre os idosos é justificada pelo autor pela influencia dos idiomas africanos; sua redução entre os mais jovens confirmaria a hipótese de descrioulização da fala da comunidade estudada. É importante sublinhar o fato de que Souza, assim como grande parte dos autores, considera pressuposicionais os enunciados negativos, não estabelecendo, no entanto, distinções pragmáticas entre as diferentes formas de negação.

${ }^{8}$ Diferentemente, os estudos de Roncarati (1996), Camargos(2000), Furtado da Cunha (2001), Schwenter (2005 e 2006) e Schwegler (1991) tratam de dialetos urbanos. 
Diferentemente dos demais autores, Furtado da Cunha (2001) utiliza um corpus que contém, além de textos de língua falada, textos de língua escrita da cidade de Natal. $\mathrm{Na}$ porção do corpus de língua falada, a pesquisadora constata uma quantidade considerável de ocorrências de negativas sentenciais não canônicas no corpus que investiga. Nos textos escritos, contudo, a negação canônica é categórica. Um fato que chama atenção na investigação da autora é a diminuição do número de ocorrência de estratégias não canônicas à medida que aumenta o grau de escolarização do falante.

A autora parece estar interessada em comprovar certas teses funcionalistas, segundo as quais no processo de variação da negação estariam envolvidos dois princípios funcionais em competição, o da iconicidade e o da economia. Dessa forma, procura explicar a trajetória das estruturas de negação em português brasileiro, encarando-as como etapas de um processo contínuo de gramaticalização. Embora faça uma revisão da literatura no que diz respeito ao valor pragmático associado às formas de negação sentencial, a autora limita-se a considerar a presença de uma negação em fim de frase como uma estratégia de pausa temática, uma digressão, ou seja, um desvio momentâneo do tópico discursivo.

Um autor que se destaca pelo trabalho de caráter abrangente, caracterizado por considerações históricas, sociais, fonológicas e pragmáticas é Schwegler. O autor em seu artigo de 1991, observa os falares de cidades dos estados de São Paulo, Rio de Janeiro e Bahia. Cabe destacar também o levantamento exaustivo das estruturas oracionais das negativas sentenciais realizado em seu estudo.

Primeiramente, Schwegler estabelece uma distinção entre tipos de sentenças que admitem as três formas de negação: declarativas em resposta a uma pergunta, declarativas espontâneas, interrogativas e imperativas. Observa que na Bahia, e no nordeste de uma forma geral, as negações não canônicas são a norma, exceto para as declarativas espontâneas. Para ele, isso seria uma evidencia de que a partícula negativa posposta perdeu seu traço enfático por um processo de desmarcação pragmática. Nas declarativas espontâneas, no entanto, a incidência menor de negação não canônica seria devida a uma distinção pragmática: NEG1 seria a forma neutra e NEG2 e NEG3 seriam pressuposicionais. Observe os enunciados que o autor utiliza para demonstrar sua afirmação.

(30) a. Quando estive no Rio, não fui na praia.

b. Quando estive no Rio, (não) fui na praia não.

Para o autor, na sentença em (a) não há pressuposição, pois ela simplesmente assevera uma proposição; na sentença em (b), há pressuposição, pois constitui uma oposição a uma correspondente afirmativa. Este último caso é ainda, segundo o autor, sentido como enfática.

Curiosamente, em determinado ponto de seu trabalho, muda sua posição quanto à diferenciação entre as três estratégias, já que, ainda no mesmo estudo, na página 204, se lê a seguinte declaração:

(...), context of discourse, must - at least provisionally - be ruled out, inasmuch as variation in the use of a given NEG seems not to coincide with 
meaningful patterns of discourse pragmatic nature, nor with clearly identifiable presuppositional differences.

Nesta passagem, diferentemente do que havia avaliado anteriormente, o autor parece considerar irrelevante qualquer fator pragmático na seleção da estratégia de negação, mantendo a posição de que a escolha depende do dialeto regional, idioleto e modalidade da sentença (declarativa em resposta a uma pergunta, declarativa espontânea, interrogativa, imperativa). Nas suas conclusões, sua posição muda novamente. Schwegler volta a considerar que o não pós-verbal em declarativas emerge somente quando o que está sendo negado é uma proposição já asseverada ou implícita no discurso precedente, o que teria sido, em momento anterior, uma característica de todas as modalidades de sentença com negação não canônica. Segundo ele, o aumento da frequência de uso teria provocado uma desmarcação pragmática.

É importante salientar uma divergência importante entre as abordagens de Schwegler e de Givón. Enquanto, para Givón, o uso da negação é por natureza pressuposicional, para Schwegler, apenas as formas não canônicas de negar veiculam conteúdo pressuposto.

Schwenter (2005) observa um corpus do falar do estado do Rio de Janeiro. O autor afirma que a negação sentencial não foi claramente especificada por outros estudos, pois esses apontavam para noções intuitivas ou não muito bem definidas do caráter enfático, pressuposicional ou contrário às expectativas. Essas postulações, apesar de serem intuitivamente aceitas facilmente, não explicam quando poderão ser utilizadas as negações não canônicas. $\mathrm{O}$ autor apresenta, então, a estrutura informacional como condição pragmática da separação, principalmente, da canônica NEG1 da não canônica NEG2. Para ele, existe uma restrição para uso de dupla negação, de que a informação negada seja velha no discurso, e não apenas velha para os interlocutores. Conforme ilustra os enunciados em (31) e (32).

(31)[Marido e mulher esperam que um encanador venha consertar um vazamento. $O$ marido chega mais cedo em casa e percebe que o encanador não veio, e que, portanto, o vazamento continua. Em seguida, sua mulher chega em casa com a mesma expectativa dele de encontrar o problema resolvido. Voltando-se para a esposa o marido profere o enunciado.]

Marido: O encanador não veio (*não).

(32) [Marido e mulher esperam que um encanador venha consertar um vazamento. $\mathrm{O}$ marido chega mais cedo em casa e percebe que o encanador não veio, e que, portanto, o vazamento continua. Em seguida, sua mulher chega em casa com a mesma expectativa dele de encontrar o problema resolvido.]

Esposa: O encanador veio?

Marido: Não veio não.

Com esses exemplos, Schwenter pretende dar suporte a hipótese de que é caráter de velho no discurso que licencia o uso de enunciados com dupla negação. Mesmo que a vinda do encanador seja conteúdo velho para os interlocutores em (31), é novo no discurso, constituindo um contexto impeditivo para o uso de NEG2. Já no exemplo (32), 
o fato de a vinda do encanador ter sido ativada discursivamente através da pergunta precedente ao enunciado negativo, torna admissível o uso da negação não canônica. Para o pesquisador, o status de discursivamente ativado pode ser alcançado por conteúdos literalmente expressos ou inferíveis. Assim, no cenário do encanador descrito acima, se a esposa chegasse e fizesse um gesto facial que o marido pudesse entender como E aí, oencanador veio?, isso seria suficiente para tornar admissível o uso de dupla negação.

Portanto, a NEG2 tem uma distribuição mais limitada que a NEG1, NEG3 por sua vez, tem uma distribuição mais limitada ainda, sendo admitida, segundo autor, apenas quando o discurso precedente apresenta o conteúdo negado de maneira literal. Conforme se observa do contraste entre (33) e (34).

(33) A: Você gostou da palestra da Maria?

B: Gostei não.

(34) Você gostou da palestra da Maria?

B1: \#Fui não.

B2: Eu não fui não.

É possível notar a partir da consideração dos diversos autores que, apesar da atenção que o tema da negação não canônica tem recebido da literatura, pouco acordo existe em relação às distinções pragmático-discursivas que existem entre as diferentes estratégias de negação. Entre os autores apresentados, Schwenter é aquele que parece avançar de modo mais decisivo na direção do estabelecimento de distinções com algum rigor conceitual.

\section{ANÁliSE CRÍTICA DAS TEORIAS PRAGMÁTICAS SOBRE A NEGAÇÃo SENTENCIAL}

Nas seções anteriores, abordaram-se diferentes autores e suas hipóteses para a ocorrência das três estratégias de negação sentencial em português brasileiro. Nesta seção, pretende-se depreender que hipóteses pragmáticas para explicar os usos da negação sentencial estão presentes nestes autores, avaliar sua plausibilidade a partir da análise de dados extraídos de entrevista sociolinguística do banco de dados do Projeto de Variação Linguística da Região Sul (VARSUL).

\section{A ANÁLISE DE GIVÓN: VIRTUDES E PROBLEMAS}

O registro feito por Givón do caráter pressuposicional presente em proferimentos de negativas sentenciais é amplamente reconhecido. Para ilustrar o que, para ele, seria uma 
evidência do estatuto pragmático especial de toda negação, o autor usa os seguinte exemplos. ${ }^{9}$

(35) Um homem não esteve em meu escritório ontem e disse...

(36) A: Quais são as novas?

B: O presidente morreu.

A: Oh, quando? Como?

(37) A: Quais são as novas?

$\mathrm{B}$ : O presidente não morreu.

A: Por quê? Ele estava mal?

Exemplos como esses parecem fornecer uma evidência bastante contundente de que a negação tem caráter pressuposicional, constituindo mesmo um ato de fala distinto da asserção. Cabe lembrar, como dito em seção anterior, que ontologicamente não eventos são uma espécie de background. Ao trazer um não evento para o foreground discursivo, o falante estaria situando a contraparte afirmativa da proposição no background, daí seu efeito pressuposicional.

Apesar do apelo intuitivo, a análise givoniana não resiste à observação de dados. A esse respeito, veja-se o trecho a seguir, extraído da entrevista SCFLP 01 do banco de dados do VARSUL ${ }^{10}$.

(38) Então a gente brincava. Então, sempre me escondia lá. Sempre me escondia [na]nessas horas de correr, de fazer ginástica- Eu gostava era de natação. Natação, eu gostava, ("de") nadar. Mas também não nadava nada, né? Não nadava, ficava só [no]no rasinho. E o meu pai dizia pra eles pra eles me ensinarem [a]- a nadar, né? não sei o que. Eu não queria saber. Não queria que ninguém chegasse perto de mim, eu queria ficar brincando.

O trecho acima apresenta várias ocorrências de negação sentencial. Para os nossos objetivos, interessa a passagem em destaque (negrito) ${ }^{11}$.

A observação do texto do trecho indica que a informação de que entrevistada não desejava aprender a nadar não pressupõe que a entrevistadora acreditasse no contrário. $\mathrm{O}$ mesmo pode ser dito do enunciado em negrito do trecho abaixo (tome $\mathrm{E}$ por entrevistador(a) e F por informante).

(39) E: Eu queria saber mais uma coisa, [tu]- tu gostas de cozinhar?

\footnotetext{
${ }^{9}$ Os exemploas 36 e 37 já haviam sido mencionados, mas para falicitar a leitura e compreensão os apresentamos novamente.

10 As entrevistas desse projeto consistem em diálogos com uma participação predominante do entrevistado, que é estimulado pelo entrevistador a fazer relatos de experiência de vida. Esses relatos são constituídos de trechos que se caracterizam pelo aspecto narrativo, entremeado de comentários esparsos sobre as situações vividas. Sendo assim, conta com enunciados com uso predominante de verbos no passado. Mesmo assim, ocorrem enunciados com verbos no presente.

${ }^{11}$ As passagens a serem analisadas estarão em negrito.
} 


\section{F: Olha, não é meu forte. Não sou muito chegada na cozinha, mas dá pra quebrar um galhinho.}

Não se pode admitir, nesse caso, uma denegação, já que o enunciado ocorre para satisfazer uma indagação do interlocutor, ou seja, não se poderia considerar que o interlocutor tivesse a crença de que a entrevistada gosta de cozinhar. Por isso, a resposta não seria um ato de negar a crença do interlocutor.

Exemplos como esses poderiam ser multiplicados indefinidamente. Parece, portanto, que, apesar do apelo intuitivo dos exemplos de Givón e de uma plausibilidade teórica para o estatuto pragmático da negação, deve existir algo a mais a determinar o caráter denegativo de enunciados negativos, ou seja, parece que a simples ocorrência de uma negação não é suficiente para dotar um enunciado de conteúdo pressuposicional.

\section{DUPLA NEGAÇÃO E PRESSUPOSIÇÃO: A HIPÓTESE DE SCHWEGLER}

Schwegler, diferentemente de Givón, quer compreender o fenômeno da dupla negação. Como vimos anteriormente, para esse autor, a dupla negação surge no português brasileiro como uma estratégia de marcação pressuposicional. Essa estratégia teria sofrido um processo de desmarcação pragmática em sentenças interrogativas, imperativas e declarativas em resposta a perguntas. Essa distinção, para ele, no entanto, permanece, no estágio atual do PFB, apenas em sentenças declarativas espontâneas.

A leitura de Schwegler sugere uma distinção funcional entre negação canônica e dupla negação em declarativas espontâneas: enquanto a primeira forma seria não pressuposicional, a segunda seria pressuposicional. Schwegler apresenta explicitamente sua hipótese para a distinção pragmática entre as diferentes estratégias de negação em declarativas negativas espontâneas.

Em declarativas, a posição do negador acrescenta importante informação pragmática ao significado básico: NEG1 (a forma não marcada) simplesmente estabelece um fato sem nenhuma pressuposição, enquanto NEG2 e NEG3 (as formas marcadas) sinalizam contradição. (Shwegler, 1991, pág.194)

No entanto, esta suposição também não resiste à análise de dados. Observe o trecho abaixo.

(40) F: Não gostava de livro de história infantil. Sempre achava muito tolo. Mas [gostava]- gostava de ler gibi. Eu adorava. Tinha um monte. Vivia lendo isso.

E: Quais eram os tipos de gibi?

F: Ah, tipo Mônica, Pantera Cor de Rosa, adorava esses filmes tudo. Filminho de televisão da (falando rindo) Pantera Cor de Rosa, amava, como e continuo amando até hoje. Adoro. (risos) Mônica, Cebolinha, ah, essas estorinhas, assim, bem bobinhas: Pato 
Donald. Queria falar igual ao Pato Donald. (risos geral) (falando rindo) Queria imitar ele falando, mas não dava certo.

E: Nunca conseguiu?

F: Nunca consegui. Não tinha jeito. Aí ficava frustrada. (risos geral) É, coisas assim, né? Mas de livro, livro não gostava não.

Nesse trecho, a passagem marcada em negrito é um caso não pressuposicional evidente de uso de dupla negação, uma vez que a enunciadora já havia esclarecido que não gostava de livros de história infantil. Assim, a interlocutora não poderia ter a crença de que a informante gostava de ler esse tipo de livro. Sendo assim, quando a entrevistada utiliza a dupla negação ela não está sinalizando uma contradição a uma crença do interlocutor. Esse caso, portanto, invalida a distinção estabelecida por Schwegler, uma vez que o enunciado em análise é uma declarativa espontânea com negação dupla que, mesmo assim, não é pressuposicional.

Para o autor, não seria possível encontrar, no atual estágio do português falado brasileiro, um enunciado de uma sentença declarativa espontânea com negação não canônica que não fosse pressuposicional. O exemplo apresentado nesta seção invalida essa hipótese. Cabe, ressaltar ainda que, nesse mesmo corpus, muitas outras sentenças poderiam ser utilizadas como exemplos de negação não canônica não pressuposicional.

\section{SCHWENTER E A HIPÓTESE DE VELHO NO DISCURSO}

Schwenter é, entre os autores que refletem sobre os aspectos pragmáticos do uso de negação sentencial em PFB, aquele que avança de modo mais decisivo no reconhecimento de suas distinções funcionais. Embora pouco acrescente a respeito da negação simples, apresenta uma análise bastante convincente sobre as restrições para os usos de negação não canônica.

Como já foi visto, a fim de compreender o uso da negação não canônica o autor estabelece uma distinção de novo e velho para o falante e novo e velho para o discurso. Nesta perspectiva, NEG2 e NEG3 só se realizam quando rejeitam conteúdos discursivamente ativados. O que diferencia NEG2 de NEG3 é o fato de que a primeira admite negar conteúdos literais ou inferíveis, a partir do discurso precedente, enquanto a segunda só admite conteúdos literais. Observe alguns casos de dupla negação retirados da entrevista, já mencionada.

(41) F: E tinha muito mato, então tinha cobra, né? Então a gente também vivia procurando cobra, procurando essas coisas-

E: Pegavam na cobra?

F: Não, pegavam na cobra não. (risos geral) (falando rindo) Não chegava a isso.

(42) F: Esse arroz à grega é gostoso, né? Tu podes juntar com passas de uva- Aliás, eu não gosto muito de passas de uva, não. Não sou muito chegada nisso, não. (falando rindo) Não é uma coisa que eu não gosto muito não. Negócio de passas de uva, eu não sou muito chegada, não. Arroz preto, aquele arroz preto, não gosto, não. 
Passas de uva, eu não gosto muito, não. Mas é interessante, que têm pessoas que gostam, né? E fica gostoso, mas é que eu não sou muito chegada, não.

Os enunciados apresentados acima parecem demonstrar que não é o caráter pressuposicional, mas o de velho no discurso que conta como restrição para o uso de negativas sentenciais não canônicas. Os exemplos apresentados pelo autor (alguns deles reproduzidos no capítulo 2 deste trabalho) e todas as outras ocorrências de dupla negação ${ }^{12}$ encontradas na entrevista analisada para este trabalho sinalizam que hipótese de Schwenter se confirma.

No quadro teórico desenvolvido por Schwenter, o critério fundamental de distinção seria o status discursivo. Segundo esse critério, a negação pré-verbal seria a forma não marcada, admitindo todas as situações pragmáticas possíveis: novo no discurso, inferível a partir do discurso, e diretamente ativada no discurso. À dupla negação caberia a marcação do que é velho no discurso (inferível ou diretamente ativado). Finalmente, à pós-verbal caberia marcar somente o que é diretamente ativado no discurso ${ }^{13}$. Esse conjunto de considerações pode visualizado na tabela a seguir.

Tabela 4: Possibilidades de uso de estratégias de negação em seu estágio inicial

\begin{tabular}{|l|l|l|l|}
\hline Forma & Novo no discurso & Inferível & $\begin{array}{l}\text { Diretamente } \\
\text { ativado }\end{array}$ \\
\hline NEG1 & OK & OK & OK \\
\hline NEG2 & $\#$ & OK & OK \\
\hline NEG3 & $\#$ & $\#$ & OK \\
\hline
\end{tabular}

Adaptado de Schwenter (2005)

Em Schwenter, a negação simples é abordada apenas para estabelecer um contraste com as formas não canônicas. Não fica claro se o autor adere ao posicionamento de Givón em relação à negação simples. Na seguinte passagem, por exemplo, o autor parece sugerir que concorda com o fato de que negação simples seja pressuposicional.

NEG1 é livre para negar expectativas que são estritamente velhas para o falante e/ou o ouvinte, mas novas no discurso, ou seja, proposições que não foram "disparadas" de nenhuma forma pelo conteúdo do discurso em curso. (Schwenter, 2005, p.1452) (14 $^{14}$

Embora o autor não seja explícito em assumir a proposta de Givón nesse trecho, em nota de rodapé para essa passagem, assume o ponto de vista de Thompson (1998), segundo o qual a negação pré-verbal tem uma função denegadora.

\footnotetext{
${ }^{12} \mathrm{O}$ corpus de analisado não apresentou nenhuma ocorrência de NEG3. Em outro trabalho verificou-se que não há ocorrências de negação pós-verbal na região sul do Brasil, há a necessidades de tentar verificar as possíveis causas que restrigem o uso de NEG3 nesta região.

${ }^{13}$ É importante esclarecer que, para Schwenter, essa divisão caracteriza o estágio inicial em uma língua qualquer de usos não-canônicos de negação. $\mathrm{O}$ autor admite, no entanto, que, com o tempo, as restrições pragmáticas percam sua força, momento em que os usos não canônicos passam a se generalizar.

${ }^{14}$ Tradução nossa.
} 
Os exemplos encontrados neste trabalho, na seção 5.1, revelam, no entanto, que não há associação estável entre NEG1 e denegação. Embora, existam casos de NEG1 que são ocorrências de denegação, os dados revelam que muitos outros não o são. $O$ caráter pressuposicional de muitas ocorrências de negação canônica, mesmo assim, parece inquestionável, o que sugere a necessidade de identificar fatores adicionais que expliquem por que determinados usos assumem esta característica pragmática.

\section{A PRAGMÁTICA DA NEGAÇÃO CANÔNICA}

Embora a pragmática da dupla negação possa ser, a partir da hipótese do Schwenter, melhor compreendida, permanece ainda algum mistério sobre a pragmática da negação canônica. Os exemplos tradicionalmente apresentados procuram sublinhar o caráter pressuposicional dessa forma de negação. Os casos apresentados por Givón, por exemplo, sugerem de modo muito forte que o simples uso de um enunciado negativo sinaliza uma disposição para se opor a algo previamente assumido.

Os exemplos encontrados para dar suporte à hipótese de que a negação é um ato outro, denegativo, curiosamente, costumam ser construídos. Apesar da observação de dados naturais ser muito comum na análise da formas não canônicas de negação, essa não tem sido uma prática adotada na análise do comportamento pragmático da negação pré-verbal. Muitos estudos costumam apenas assumir como dado que essa forma de negar é pressuposicional, sem que qualquer inspeção mais cuidadosa de dados resultantes de coleta de fala espontânea.

Nesta seção, procura-se suprir essa lacuna apresentando-se dados naturais de negação pré-verbal extraídos da entrevista do projeto VARSUL. O objetivo é verificar se esses enunciados com negação pré-verbal confirmam a hipótese de Givón, que acredita que toda negação é pressuposicional, ou a de Schwegler, para quem a negação pré-verbal é uma forma não marcada e, portanto, não pressuposicional. A seguir, estão os trechos com enunciados negativos a serem considerados.

(43) E: Tu, tu gostavas, assim, de história em quadrinhos, essas coisas, já que falaste na Mônica?

F: Gostava, ler gibi, ih! adorava, passava - Isso aí era uma- Adorava, adorava, adorava, adorava. Não gostava de livro de história infantil. Sempre achava muito tolo. Mas gostava de ler gibi. Eu adorava. Tinha um monte. Vivia lendo isso.

(44) E: Quais eram os tipos de gibi?

F: Ah, tipo Mônica, Pantera Cor de Rosa, adorava esses filmes tudo. Filminho de televisão da (falando rindo) Pantera Cor de Rosa, amava, como continuo amando até hoje. Adoro. (risos) Mônica, Cebolinha, ah, essas estorinhas, assim, bem bobinhas, Pato Donald. Queria falar igual ao Pato Donald. (risos geral) (falando rindo) Queria imitar ele falando, mas não dava certo.

(45) E: Já que tu gostavas tanto assim de ler, (hes) eu notei, assim, que [tu não]- tu não perseguiste no estudo, né?

F: Ah, pois é.

Cadernos do IL. Porto Alegre, n. ${ }^{o} 42$, junho de 2011. p. 236-259. 
E: E [por que]- por que aconteceu isso?

F: Ah, porque eu fiquei doente. Eu tive- Como é que a gente fala? Laringite, não, meningite, é. (falando rindo) Já estou ficando louca. Meningite, tive meningite, daí eu não pude prosseguir, né? Aí eu deitada não tinha condições, né? de ir.

(46) E: Na Marinha, também, [na Marinha eu fazia chantagem]- na Marinha eu fazia chantagem. Eu adorava, que eu sou gordinha, né? adorava (hes) um suquinho, [um negócio] (hes) comer, né? Então, quando eles não queriam dar pra mim (hes), quer dizer, (falando rindo) o suco, né? aí, eu dizia que eu ia contar pro meu pai que eles tinham me batido, e abria berreiro. Então, eu era a única que tomava suco, assim, a torto e a direito. Porque eu começava a chorar, que o meu pai era muito brabo, eu ia dizer pra todo mundo que eles tinham me batido. Então [era um]- era um- Eles não gostavam muito de mim também, né?

(47) Sempre me escondia [na]- nessas horas de correr, de fazer ginástica. Eu gostava era de natação. Natação, eu gostava, ("de") nadar. Mas também não nadava nada, né? Não nadava, ficava só [no]- no rasinho.

(48)F: Não nadava, ficava só [no]- no rasinho. E o meu pai dizia pra eles pra eles me ensinarem, a nadar, né? não sei o que. Eu não queria saber. Não queria que ninguém chegasse perto de mim, eu queria ficar brincando.

(49) F: Até que chegou um dia que eu ganhei uma sombrinha linda. A sombrinha era maravilhosa, a coisa mais linda. Aí, (ruído) queria porque queria ir com a sombrinha pro colégio, né? e a mãe não deixou porque era muito bonita e a mãe já sabia, né?

(50) Aí, meu avô só ficava reparando isso. Aí chegou [num]- num determinado dia, a gente sempre nesse rolo. É, eu olhando o resto da a comida e ela só queria comer arroz. (falando rindo) Aí, pra ela, ele mandou fazer um panelão de arroz. Mas um panelão enorme, enorme. Naquele dia, ela almoçou só arroz, só arroz, não comeu mais nada.

(51)F: Sempre faz aquelas coisas que não pode. [A gente se <pendu->]- não era pendurar, também, né? Nós gostávamos de abrir o armário porque ele era muito grande, e era muito alto. (falando rindo) Então a gente se pendurava aí, e ficava assim. (f) Quando ia pegar um copo, uma coisa, fazia: "Opa"! Sabes aquela história? E um dia (falando rindo) (inint) quebrou tudo. [Foi]- foi copo, prato pra tudo quanto era lado. A minha avó quase teve um enfarto coitada. Ficou louca! Ficamos de castigo- Eu não estava nessa. [Estava [na]- [na]- eu não me pendurei, né? Mas ela não quis nem saber. Foi todo mundo de castigo.

(52) Me lembro, numa época que a minha irmã quebrou o braço, que eu pedia pra ela bater no meu (falando rindo) pra mim quebrar também, mas [não tinha]- não quebrava. (risos) 
(53) F: Ah, [e na]- pra cuidar da casa do meu avô, que era grande, né? Então a minha avó não gostava de empregada, mas ela tinha um ajudante. Mas, esse ajudante era completamente louco, era a $\mathrm{F}<$ completa- $>$ - É, ele tinha sido internado e tudo, já.

Contrariamente ao que fazem supor os exemplos de Givón, na maioria dos casos apresentados a negação não é pressuposicional. A única exceção parece ser o enunciado (47), que parece ser pressuposicional. Nesse enunciado, o falante parece estar buscando desfazer uma possível crença do interlocutor. Essa possível crença tem como origem o próprio discurso precedente do falante. Ao afirmar que gostava de natação e de nadar, estimula a crença de que sabia nadar. No entanto, o caráter pressuposicional desse enunciado não está necessariamente associado ao uso da negação. Digna de nota, nesse caso, é a presença da expressão mas também, que cuja função parece ser a de a de marcar formalmente um ponto de vista contrário.

A maioria dos exemplos, portanto, sugere que o caráter pressuposicional da negação pré-verbal não pode ser considerado um padrão. Caberia ainda perguntar se não são os usos pressuposicionais que constituem uma exceção à regra. Para tanto, seria interessante encontrar uma característica comum aos exemplos pressuposicionais que pudesse explicar essa impressão. Se essa característica puder ser identificada, então poder-se-á atribuir a ela, ou a sua associação com a negação, o caráter pressuposicional normalmente aceito. A esse respeito, tomemos os exemplos já citados em seções anteriores e o a seguir.

A: Eu não via a Maria chegando tarde ontem.

Um traço comum de ambos os casos é o de serem abertura de um tema. É bem provável que esse seja um contexto bastante restritivo ao uso de negações. Espera-se de um falante que começa a falar de um assunto a apresentação de algum dado positivo. Não é de estranhar, portanto, que o início de discurso com uma negação seja sentido como pressuposicional, ou seja, como a continuação de um assunto já iniciado. Como o assunto, nesses casos, não foi de fato iniciado, tende-se a supor um início que só poderia ser constituído pela contraparte afirmativa do enunciado inicial.

\section{CONSIDERAÇÕES FINAIS}

A negação, de um modo geral, tem apresentado desafios para as teorias pragmáticas. Fenômenos como a concordância negativa, a negação metalinguística e as diversas formas de negar uma sentença têm instigado os estudiosos da Pragmática, no sentido de determinar quais seriam as particularidades discursivas de tamanha diversidade de recursos que subjazem a produção de enunciados negativos. Particularmente desafiadoras são as línguas que apresentam diferentes estratégias de negação sentencial, nas quais varia a posição e a quantidade de operadores negativos, entre elas, o português falado no Brasil. 
Este trabalho, partindo de distinções existentes na literatura, buscou identificar os pontos de vista mais articulados sobre as funções pragmáticas das estratégias de negação. Procurou-se apontar os ganhos das abordagens apresentadas, bem como suas inconsistências. Uma das conclusões que podem ser anunciadas é a de que a hipótese de Schwenter $(2005,2006)$ a respeito das restrições pragmáticas envolvidas no uso de negações está correta, contrapondo-se ao que é assumido por Schwegler.

A hipótese de Givón, quanto ao caráter pressuposicional e denegativo da negação canônica, no entanto, não recebe comprovação da análise dos dados considerados neste trabalho. Os dados analisados apresentam usos predominantemente não pressuposicionais de negação pré-verbal. Nesse aspecto, portanto, Schwegler parece estar correto, embora esteja equivocado quanto ao uso de negações nãocanônicas.

Com os resultados obtidos, espera-se contribuir para a compreensão da pragmática das estratégias de negação no português falado no Brasil. A compreensão dessas restrições pragmáticas, além de ampliar o entendimento de fenômenos da significação em linguagem verbal, pode, em alguma medida, colaborar para outros estudos, como os da Sociolinguística Variacionaista, que, a partir do trabalho de alguns autores (alguns deles abordados neste trabalho) tenta determinar se a língua falada no Brasil encontra-se em algum dos estágios do ciclo de Jespersen. A consideração de fatores pragmáticos pode refinar os estudos sociolinguísticos, uma vez que poderiam ser incorporados às variáveis de análise que integram o envelope de variáveis linguísticas destinadas a avaliar o fenômeno variável da negação.

\section{REFERÊNCIAS BIBLIOGRÁFICAS}

BLACKEMORE, D. Relevance and linguistic meaning: the semantics and pragmatics of discourse markers. Cambridge: Cambridge University Press, 2002.

CAMARGOS, Marcelo. (2000). A negativa: uma análise qualitativa. Disponível em http://www.ufop.br/ichs/conifes/anais/LCA/clca03.htm. Acessado em 12 de maio de 2009.

CARSTON, R. Metalinguistic negation and echoic use. Journal of pragmatics, v. 25, 1996.

FURTADO DA CUNHA, M. A. O modelo das motivações competidoras no domínio funcional da negação. DELTA: Documentação de Estudos em Linguística Teórica e Aplicada, São Paulo, 2001.

GIVÓN, Talmy. Negation in language: pragmatics, function, ontology. Syntax and semantics 9: Pragmatics, ed. by Peter Cole, 69-112. New York: Academic Press, 1978.

GIVÓN, Talmy. Negation. In:__. Syntax: a functional-typological introduction. Vol. I. Amsterdam / Philadelphia: John Benjamins, 1984.

GOLDNADEL, Marcos. Capítulo 2: Os desafios da negação. In:

Pressuposição Radicalmente Pragmática. Porto Alegre: PUC-RS, 2004. Tese (Doutorado em Linguística Aplicada) - Programa de Pós-Graduação em Letras, Faculdade de Letras, Pontifícia Universidade Católica, Porto Alegre, 2004. 
GUEDES, Carla Fernanda Ferreira. (2001). Capítulo 1: Considerações gerais sobre negação. In: . Sujeitos Negativos e Concordância Negativa em Português numa perspective de Sintaxe Comparada. Porto: Universidade do Porto, 2001. Dissertação (Mestrado em Letras) - Programa de Pós-graduação em Letras, Faculdade de Letras da Universidade do Porto, Porto: 2001.

HORN, L. Metalinguistic negatiuon and pragmatic ambiguity. Language, V. 61, n. 1, 1985.

HORN, L. A natural history of negation. Stanford: CSLI, 2001.

ILARI, R. Perspectiva funcional da frase portuguesa. Campinas: Editora da UNICAMP, 1992.

LAMBRECHT, K. Information structure and sentence form. Cambridge: Cambridge University Press, 1994.

LEVINSON, S. Presumptive meanings. Cambridge: MIT Press, 2000.

RONCARATI, Cláudia. A negação no português falado. IN: MACEDO, Alzira Tavares de; RONCARATI, Cláudia; MOLLICA, Maria Cecília. (orgs). Variação e discurso. Rio de Janeiro: Tempo Brasileiro, 1996.

SCHWEGLER, Armin. Predicate negation in contemporary Brazilian Portuguese - A linguistic change in progress." Orbis 34:187-214, 1991.

SCHWENTER, Scott A. The pragmatics of negation in Brazilian Portuguese. Lingua 115.1427-56, 2005

SCHWENTER, Scott A. Fine-Tuning Jespersen's Cycle. In:Drawing the Boundaries of Meaning: Neo-Gricean Studies in Pragmatics and Semantics in Honor of Laurence R. Horn, ed. by Betty J. Birner and Gregory Ward. Amsterdam: Benjamins, 2006.

SOUSA, Arivaldo Sacramento. (2004). As estruturas de negação em uma comunidade rural afro-brasileira:Helvécia -BA. [online]. Disponível em http://www.vertentes.ufba.br/souza.doc. Acessado em Maio de 2009. 